\title{
THE EVOLUTION OF DOMINANCE IN CERTAIN POLYMORPHIC SPECIES
}

\author{
R. A. FISHER, Sc.D., F.R.S. \\ STATISTICAL DEPARTMENT, ROTHAMSTED EXPERIMENTAL STATION, \\ HARPENDEN, HERTS, ENGLAND
}

\section{SELECTIVE EQUILIBRIUM IN POLYMORPHIC SPECIES}

IN his very interesting contribution to the problem of the evolution of dominance, published in the AMERICAN NATURALIST of January, 1930, Mr. J. B. S. Haldane calls attention to the peculiar dominance phenomena found by Nabours in the grouse locusts Paratettix and Apotettix, and by Winge in the fish Lebistes reticulatus. These, and I shall suggest that some of the land-snails such as Helix hortensis and $H$. nemoralis should be added to the list, have each of them three remarkable characteristics in common. The wild forms are all visibly polymorphic. The polymorphism may in each case be shown to be determined by genes or gene-complexes which are very closely linked in inheritance. Finally, each species has a relatively common "universal recessive," together with a number of usually less common dominant forms, which, if allelomorphic, show no mutual dominance, but have heterozygotes combining the characteristics of the two dominant homozygotes. The recessiveness of the "uni versal recessive," apart from rare deviations in some compound types produced in culture, seems to be complete.

Haldane had previously suggested with respect to the grouse locusts, and Demerec later with respect to Lebis- 
tes, that the close linkage and frequent apparent allelomorphism observed in these groups was due not only to the infrequency of crossing over in their chromosomes, but to several chromosomes received from the same parent being generally transmitted in a group to the same offspring, Haldane now, with the support of C. D. Darlington and C. L. Huskins, has suggested that such linkage between chromosomes may be accounted for by sectional translocations, and that the dominant genotypes are themselves due to the duplication of such translocated segments. While some explanation of this kind appears to the writer extremely attractive in respect of the very close and frequent linkage observed, it is not so plain in what manner Haldane finds in it an explanation of the dominance phenomena. He says, "On the theory here adopted we need only suppose that some of the genes in the duplication have a greater effect when three or four are present than when only two are found, as in the normal type." This would indeed suffice to explain why the heterozygous duplication should differ from the universal recessive. But it gives no explanation of the completeness of dominance; it does not explain why the homozygous duplication should resemble the heterozygote. For this it is necessary to suppose, not only that some of the genes in the duplication have a greater effect when three are present, but also that none of them should exert a further effect when the three are increased to four; and this curious type of limitation must be observed in each of the possible duplications to which the different dominants are to be ascribed. Attractive as the suggestion is, therefore, in respect to linkage, it can not be regarded, as it stands, in any sense as an explanation of the dominance observed in these groups.

In previous papers (Fisher, $1928 a$ and 6) I have developed a theory of the evolution of dominance by the natural selection of modifying factors, and have applied it to explain the generally observed recessiveness of deleterious mutants exposed to counter-selection, yet maintained at an extremely small frequency in the stock 
by persistent mutation. Haldane seems to draw an analogy between such mutants and the less numerous genotypes of polymorphic species without sufficient circumspection. There is no good ground for regarding the less numerous genotypes of polymorphic species as subjected to counter-selection and only maintained in the stock by persistent mutation; indeed, the frequency with which they appear in nature would, unless the counterselection postulated were exceedingly minute, require such enormous mutation rates as would inevitably have been detected in much less extensive experiments than those of Nabours and Winge. Mendelizing polymorphism may, on the contrary, be maintained indefinitely, as is probably the case with several polymorphic butterflies (Fisher, 1927), by a balance of selective actions, under which the frequency ratio of the contrasted genes settles down to a condition of equilibrium, which will be stable, to take the simplest case, if the heterozygote is at a selective advantage compared to both homozygotes. Since in the opposite case, when the heterozygote is the least advantageous phase, the equilibrium will be unstable and one or other homozygote must be exterminated, we should not expect to find such factors in nature. Stability, brought about by a favored heterozygote, may, on the contrary, be not uncommon, and there is some evidence in the case of the butterflies alluded to that the opposing selective forces consist on the one hand of the bionomic advantage of a mimetic or otherwise advantageous coloring, and on the other of some physiological factor such as inferior viability or fertility, associated with the dominant homozygote. Such cases appear to offer the unparalleled opportunity of estimating the magnitude of a bionomic advantage in nature by direct observation of the frequency of contrasted genotypes in the wild population, together with the experimental determination of the extent of inviability or sterility.

In this regard Nabour's genetical study of the grouse locusts has opened out a field of extraordinary interest. Haldane's remark, "Now on Fisher's theory there is no 
obvious reason why modifiers should not be able to suppress the effect of a duplication as easily as that of a gene," may now be accepted in its full force, for there is no reason to suppose that the effects of the duplications, if duplications they are, have been exposed to counter-selection. Indeed, there are two reasons why the selection of dominance modifiers should be particularly effective in such cases. In the first place, the heterozygotes in which the effect of such modifiers is exposed to selection are now a perceptible percentage of the wild population, instead of having a frequency of the order of 1 in 10,000. This must increase the selective intensities about 100 or 1,000 fold, so that the difficulty felt by critics such as Wright and Haldane, who feel that in the case of deleterious mutations the selective intensities at work are too minute to have produced great results, is here removed. In the second place, if, as Haldane suggests, the dominant forms are due to a duplicated tract of chromatin, the evolutionary modification of this tract will take place almost wholly in heterozygous individuals. The selective advantage of any gene-contrasts within this tract will be totally unaffected by any reaction they might have produced in the "universal recessive," or in other dominant types. One may say that such a portion of chromatin is reserved for the evolutionary improve ment of each particular heterozygote, and in less degree of the corresponding dominant homozygote.

Even without postulating duplication, a similar result will follow if, as is made probable by the high linkages observed, each dominant gene is situated in a section of chromatin in which crossing over never takes place. The evolutionary progress of such a section would then be wholly conditioned by the quality of its effects in the presence of the dominant gene. The modification of the extent of dominance through evolutionary changes in permanently associated genes bears some resemblance to Haldane's own views in depending on the selection rather of multiple allelomorphs than of multiple factors, for he has suggested that multiple allelomorphism is also re- 
sponsible for the evolution of dominance against single defective gene mutations - an important suggestion, though made, I believe, for the wrong reason, for it is difficult to believe that the evolution will be hastened by throwing the whole burden on to one factor only out of the many thousands present, even though this one is clearly the most relevant.

The severest test of a theory is to build upon it a sys tem of inferences, for if any rigorously logical inference is found to be untrue the theory fails. If, on the contrary, facts previously unsuspected are inferred from the theory, and found on trial to be true, the theory is undoubtedly strengthened. The plain inference from the theory of the modificatory selection of dominance and the fact that one particular pattern in the grouse locusts is recessive to all its natural alternatives is that this particular pattern is less advantageous than any of the others. This may seem surprising since this particular pattern is often, perhaps always, the most numerous in nature. We have, however, inferred only one half of the selective balance. The selective advantage of the heterozygote over the homozygous recessive is inferred from the fact of dominance to be due to its pattern. If there is a balance of selective agencies, the heterozygote must also enjoy some advantage over the homozygous dominant. In this contrast the patterns are alike, and we should naturally look for some constitutional difference affecting viability or fertility. Such a constitutional deficiency again accords well with the theory that we have to do with a homozygous duplication. It is of more direct consequence to our argument that a deficiency of homozygous dominants of sufficient magnitude to be statistically significant appears from the published record of Nabour's breeding experiments.

\section{VIABILITY OF HOMOZYGOTES}

In order to examine the evidence as to the viability of homozygotes, an exhaustive examination was made of the 
very large body of data reported by Nabours in his experiments with Apotettix (Nabours, 1925).

Matings from which homozygotes of the dominant forms appear are necessarily unsuitable for studies of linkage. Only a minority of Nabour's experiments can therefore be available for studying their viability. In matings of the generalized type P/Q X P/Q homozygotes and heterozygotes should appear in equal numbers, or, strictly, in proportion to their viability up to the time of classification. A comparison between the observed frequencies in such matings should, therefore, if the material proves to be sufficiently ample, supply an indication of any existing difference in viability. These matings will, however, show a certain small proportion of recombined types, some of which are not phenotypically separable from the three main types of offspring, and although the frequency of recombination is small, it is important that the treatment of the recombined types should allow of no bias in the massed comparisons.

Of the four recombined types which should appear in equal numbers two, namely, $\mathrm{P} /+$ and $\mathrm{Q} /+$, will have been classified as homozygotes, while the remaining two, P/PQ and $\mathrm{Q} / \mathrm{PQ}$, will generally have been classed as heterozygotes ; exceptionally, as with the mating Y/T X Y/T, these latter classes are recorded separately, and in such cases they have been added to the heterozygotes. If viability is equal, crossing over thus introduces no bias into the main comparison, though by classifying a small proportion of homozygotes as heterozygotes and an equal proportion of heterozygotes as homozygotes the effect sought for will certainly be diluted.

If $\mathrm{p}$ is the recombination fraction, and $\mathrm{q}=1-\mathrm{p}$, the viability ( $v$ ) as determined from the frequency ratio of the offspring as classified will be related to the true viability $\mathrm{v}_{0}$, by the equations

$$
v=\frac{q v_{0}+p}{q+p v_{0}}, \quad v_{0}=\frac{q v-p}{q-p v},
$$


which may be used to correct the estimates obtained. Such corrections can not, of course, influence the test of significance.

Many of the matings are, however, of the type $P Q / R X$ $\mathrm{PQ} / \mathrm{R}$. In addition to the possible recombination of $\mathrm{PQ}$ and $\mathrm{R}$, we have here also the two additional types of recombination involving the separation of $\mathrm{P}$ from $\mathrm{Q}$. Thus the recombined gametes $\mathrm{P}$ and $\mathrm{QR}$ will yield zygotes $\mathrm{PQ} / \mathrm{P}$ and $\mathrm{PQ} / \mathrm{QR}$ which will be classified as $\mathrm{PQ} / \mathrm{PQ}$ and $\mathrm{PQ} / \mathrm{R}$, respectively, together with two independently classified zygotes $\mathrm{R} / \mathrm{P}$ and $\mathrm{R} / \mathrm{QR}$. Bias may in this case be avoided by classing these with $\mathrm{E} / \mathrm{PQ}$ and $\mathrm{R} / \mathrm{R}$, respectively, and the same convention is applied in the classification of the recombined zygotes R/Q and R/PR, whenever they occur. In this case also there will be some dilution of the effect sought for, but its test of significance is unaffected.

Table I gives the frequencies for the forty types of mating available, the reference numbers in the first column giving the first mating of each type. The crossovers capable of separate classification are in each case shown on a separate line, in the column to which they have been assigned. In the aggregate 4,309 homozygotes and 4,617 heterozygotes survived to be classified. This is a very considerable defect of homozygotes, not to be ascribed to chance, since it exceeds three times its standard error. The massed data demonstrate an appreciable defect of homozygotes. The percentage viability is about 92.9 per cent. of that of the heterozygotes.

In respect of individual dominants the data are necessarily less ample, though here also there are some cases which must be judged to be individually significant, and in all these the deficient class is that of the homozygotes. Table II shows the aggregate of homozygotes and heterozygotes for each dominant or compound of dominants tested. The dominants $\mathrm{Y}, \mathrm{O}$ and $\mathrm{R}$ and the compounds $\mathrm{RK}, \mathrm{YK}$ and MR all show individually significant deficiencies, while $M$, T, G, Z, YT and YZ all show deficiency in less degree. The cases of RK and $\mathrm{YK}$ are especially 
TABLE I

Matings of TrPe $P / Q \times P / Q$

\begin{tabular}{|c|c|c|c|c|c|}
\hline Mating & Parents & $\begin{array}{l}\text { Homo- } \\
\text { zygotea }\end{array}$ & $\begin{array}{l}\text { Hetero- } \\
\text { sygotes }\end{array}$ & $\begin{array}{l}\text { Homo- } \\
\text { zygotes }\end{array}$ & Crossovers \\
\hline 370 & $\mathrm{H} / \mathrm{G}$ & 15 & 28 & 15 & \\
\hline 375 & $\mathrm{M} / \mathrm{R}$ & 49 & 115 & 54 & \\
\hline 391 & M/W & 27 & 47 & 26 & \\
\hline 397 & $\mathrm{M}^{\prime} / \mathrm{T}$ & 58 & 95 & 54 & \\
\hline 399 & $\mathrm{M}^{\prime} / \mathrm{G}$ & 76 & 147 & 83 & \\
\hline 405 & $M^{\prime} / K$ & 238 & 556 & 292 & \\
\hline 422 & $\mathrm{Y}^{\prime} / \mathrm{O}$ & 9 & 26 & 9 & \\
\hline 431 & $\mathrm{Y} / \mathrm{R}$ & 65 & 185 & 86 & \\
\hline 439 & $\bar{Y} / Z$ & 71 & 145 & 72 & \\
\hline 447 & $\mathrm{Y} / \mathrm{T}$ & 12 & 48 & 22 & \\
\hline 452 & $\mathrm{YT} / \mathrm{O}$ & 14 & 42 & 14 & \\
\hline 458 & $Y / K$ & 33 & 69 & 37 & \\
\hline 470 & $\sigma^{\prime} / \mathrm{R}$ & 16 & 46 & 30 & \\
\hline 471 & $\mathrm{o}^{\prime} \mathrm{T}$ & 18 & 24 & 14 & \\
\hline 474 & $0 / G$ & 40 & 105 & 51 & \\
\hline 482 & $\mathrm{O} / \mathrm{K}$ & 8 & 28 & 8 & \\
\hline 487 & $\mathrm{R} / \mathrm{T}$ & 35 & 90 & 32 & \\
\hline 492 & $\mathrm{R}^{\prime} / \mathrm{K}$ & 88 & 168 & 100 & \\
\hline 510 & $\mathrm{w} / \mathrm{K}$ & 74 & 138 & 75 & \\
\hline 517 & $\mathrm{Z} / \mathrm{K}$ & 20 & 35 & 13 & \\
\hline 524 & $\mathrm{Z} / \mathrm{T}$ & 25 & 35 & 15 & \\
\hline 525 & $\mathrm{~T} / \mathrm{G}$ & 32 & 62 & 27 & \\
\hline 528 & $\mathrm{~T}^{\prime} / \mathrm{K}$ & 40 & 64 & 35 & \\
\hline 541 & $\mathrm{MR} / \mathrm{K}$ & 69 & $\begin{array}{r}181 \\
2\end{array}$ & $\left.\begin{array}{r}110 \\
3\end{array}\right\}$ & 5 \\
\hline 553 & $\mathrm{M} / \mathrm{RK}$ & 85 & 167 & $78^{\prime}$ & \\
\hline 569 & $\overline{Y Z} / \mathrm{T}$ & 49 & $\begin{array}{r}85 \\
5\end{array}$ & $\left.\begin{array}{r}25 \\
1\end{array}\right\}$ & 6 \\
\hline 571 & $\mathrm{YZ} / \mathrm{G}$ & 138 & $\begin{array}{r}258 \\
4\end{array}$ & $\left.\begin{array}{r}110 \\
4\end{array}\right\}$ & 8 \\
\hline 577 & $\mathrm{YZ} / \mathrm{K}$ & 96 & $\begin{array}{r}192 \\
8\end{array}$ & $\left.\begin{array}{r}103 \\
5\end{array}\right\}$ & 13 \\
\hline 584 & $\mathrm{YT} / \mathrm{R}$ & 134 & $\begin{array}{l}312 \\
-\end{array}$ & $\left.\begin{array}{r}149 \\
1\end{array}\right\}$ & 1 \\
\hline 605 & $\mathrm{YK} / \mathrm{O}$ & 21 & 48 & 22 & \\
\hline 612 & $\mathrm{YK} / \mathrm{R}$ & 184 & $\begin{array}{r}423 \\
4\end{array}$ & $\left.\begin{array}{r}158 \\
4\end{array}\right\}$ & 8 \\
\hline 623 & $\mathrm{YK} / \mathrm{Z}$ & 18 & 43 & 9 & \\
\hline 624 & $\mathrm{YK} / \mathrm{T}$ & 51 & $\begin{array}{r}108 \\
7\end{array}$ & $\left.\begin{array}{r}48 \\
1\end{array}\right\}$ & 8 \\
\hline 627 & $\mathrm{YT} / \mathrm{K}$ & 29 & $\begin{array}{r}35 \\
6\end{array}$ & $\left.\begin{array}{r}20 \\
3\end{array}\right\}$ & 9 \\
\hline 631 & $\mathrm{RK} / \mathrm{T}$ & 142 & 315 & $\left.\begin{array}{r}138 \\
1\end{array}\right\}$ & 1 \\
\hline 635 & B $/$ MRK & - & 1 & - & \\
\hline 636 & $\mathrm{MRK} / \mathrm{T}$ & 5 & 20 & 4 & \\
\hline 640 & YK /RK & - & 9 & 4 & \\
\hline 641 & $\mathrm{YRK} / \mathrm{G}$ & 8 & $\begin{array}{l}7 \\
2\end{array}$ & $\left.\begin{array}{l}5 \\
1\end{array}\right\}$ & 3 \\
\hline 643 & $\mathrm{YZ} / \mathrm{RK}$ & 27 & 77 & 24 & \\
\hline & tal …..... & 2,119 & 4,617 & 2,190 & \\
\hline
\end{tabular}


TABLE II

\begin{tabular}{|c|c|c|c|}
\hline Factor & Homozygotes & Heterozygotes & $\begin{array}{l}\text { Estimated } \\
\text { viability } \\
\text { per eent. }\end{array}$ \\
\hline \multicolumn{4}{|c|}{$\begin{array}{l}\text { Dominants showing signifieant } \\
\text { defieieney }\end{array}$} \\
\hline $\begin{array}{l}\mathbf{Y} \\
\mathbf{R} \\
\mathbf{R K} \\
\mathbf{Y K} \\
\mathbf{M R}\end{array}$ & $\begin{array}{r}190 \\
127 \\
605 \\
243 \\
274 \\
69\end{array}$ & $\begin{array}{r}473 \\
319 \\
1343 \\
568 \\
642 \\
183\end{array}$ & $\begin{array}{l}80.3 \\
79.6 \\
90.1 \\
85.6 \\
85.4 \\
75.4\end{array}$ \\
\hline \multicolumn{4}{|c|}{$\begin{array}{l}\text { Dominants showing non-signifi- } \\
\text { eant deficieney }\end{array}$} \\
\hline $\begin{array}{l}\mathbf{M} \\
\mathbf{T} \\
\mathbf{G} \\
\mathbf{Z} \\
\mathbf{B} \\
\mathbf{Y T} \\
\mathbf{Y Z} \\
\mathbf{M} R \mathbf{\ldots}\end{array}$ & $\begin{array}{r}533 \\
427 \\
296 \\
126 \\
0 \\
177 \\
310 \\
5\end{array}$ & $\begin{array}{r}1127 \\
958 \\
613 \\
258 \\
1 \\
395 \\
629 \\
21\end{array}$ & $\begin{array}{l}94.6 \\
89.1 \\
96.6 \\
97.6 \\
89.6 \\
98.6 \\
\end{array}$ \\
\hline \multicolumn{4}{|c|}{$\begin{array}{l}\text { Dominants showing non-signiff- } \\
\text { cant excess }\end{array}$} \\
\hline $\begin{array}{l}\mathbf{K} \\
\mathbf{W} \\
\text { YRK }\end{array}$ & $\begin{array}{r}804 \\
100 \\
15 \\
8\end{array}$ & $\begin{array}{r}1482 \\
185 \\
28 \\
9\end{array}$ & $\begin{array}{r}108.5 \\
108.1 \\
- \\
-\end{array}$ \\
\hline Total & 4309 & 9234 & 93.3 \\
\hline
\end{tabular}

interesting, since $\mathrm{K}$ is the only dominant for which substantial data are available which by itself shows no deficiency of homozygotes. The only other cases of excess

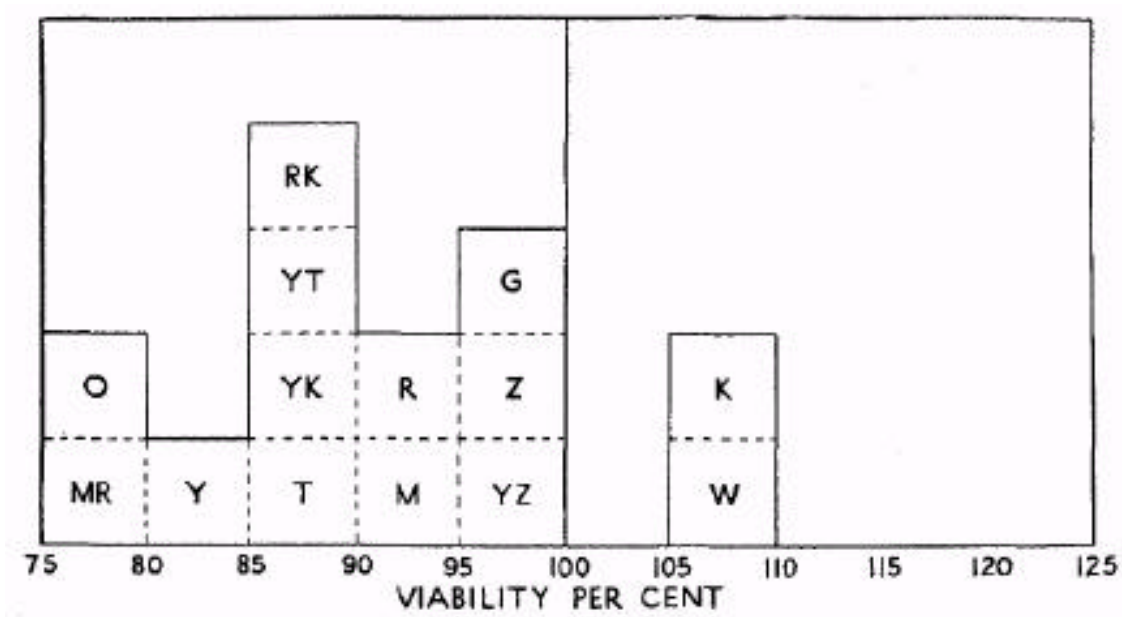


are shown by W with only 285 observations, by $\mathrm{H}$ with only 43 and by YRK with only 17.

Fig. 1 shows the distribution of the fourteen viabilities, based each on over 200 survivors. The true viabilities will, as has been seen, be generally somewhat lower than those shown, which have not been corrected for dilution due to recombination.

The deliberate experimental determination of the selective viabilities of different homozygous and heterozygous types would evidently be of great value in clearing up the situation. In particular, though, on the view suggested, there is no reason to anticipate that the viability of the homozygous recessives should be inferior to that of the heterozygotes, there is some, though still inconclusive, evidence from Nabour's matings that this homozygote also may be at a slight disadvantage. Four types of matings are available on this point.

(i) When homozygous recessives $(+/+)$ are mated with heterozygotes (+/Q) where $\mathrm{Q}$ stands for a dominant or compound of dominants, homozygotes and heterozygotes are expected in equal numbers. In this ease all crossovers in the dominant compound are recognizable, and may be omitted. These matings are shown in Table III.

TABLE III. $+/+x+/ Q$

\begin{tabular}{ccc}
\hline Mating & $+/+$ & $+/ Q$ \\
\hline 4 & 20 & 8 \\
5 & 3 & 6 \\
6 & 33 & 32 \\
351 & 6 & 9 \\
721 & 31 & 36 \\
\hline & Total $\ldots 3$ & 91 \\
\hline
\end{tabular}

This group gives 93 homozygous recessives to 91 heterozygotes, and shows no defect of homozygotes.

(ii) When like heterozygotes (+/Q) are interbred, a quarter homozygous recessives are expected, but the homozygous dominants can not be distinguished from the heterozygotes; only two of the four crossover classes are 
distinguishable, the other two being confounded with the heterozygote and homozygous dominants. We may therefore subtract the number distinguishable from the number in this class. These matings are shown in Table IV.

TABLE IV. $+/ Q \times+/ Q$

\begin{tabular}{crrc}
\hline Mating & $+/+$ & \multicolumn{1}{c}{$Q$} & Crossovers \\
\hline 287 & 77 & 114 & - \\
292 & 2 & 10 & - \\
312 & 4 & 12 & - \\
316 & 5 & 24 & - \\
348 & 5 & 16 & - \\
352 & 24 & 82 & - \\
365 & 14 & 51 & - \\
443 & 32 & 118 & 4 \\
469 & 26 & 91 & -11 \\
521 & 4 & 11 & 1 \\
1246 & 221 & 611 & 16 \\
& & 16 & \\
& & 595 &
\end{tabular}

This group gives 221 recessives to 595 heterozygous and homozygous dominants, and shows an appreciable excess of recessives. This is due, however, principally to the great excess shown in mating 287, which the other matings as a whole tend partially to counterbalance.

(iii) When heterozygotes $+/ \mathrm{P},+/ \mathrm{Q}$ are mated, the expectation is again a quarter recessives. If $\mathrm{P}$ and $\mathrm{Q}$ are compounds containing no dominant in common all the nonrecessives will be heterozygotes, and all crossovers will be theoretically capable of detection. Those detected have therefore been omitted; Table $\mathrm{V}$ shows eighty-six types of mating of this class.

These give in all 1,732 recessives to 5,466 heterozygotes, a deficiency of recessives which only just falls short of twice the standard error. It is the material in Table $\mathrm{V}$ which makes it worth while to call attention to the possibility of making more direct tests of the viability of the recessive type, for though the data as they stand can not

* Results of mating 287 should be omitted. - R.A.F. 
TABLE V. +/P X +/Q

\begin{tabular}{|c|c|c|c|c|c|c|c|c|c|c|c|}
\hline 莺 & & \pm & 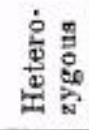 & 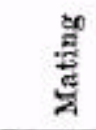 & & $\stackrel{+}{+}$ & 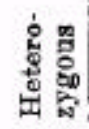 & 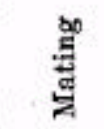 & & $\stackrel{ \pm}{+}$ & 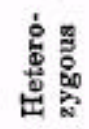 \\
\hline 275 & ㄷ….... & 5 & 21 & 755 & ........... & 38 & 118 & 1085 & $\ldots$ & 11 & 55 \\
\hline 277 & $=$ & 22 & 103 & 757 & & 36 & 142 & 1099 & & 27 & 55 \\
\hline 282 & - & 15 & 63 & 837 & $\ldots$ & 2 & 6 & 1103 & - & 1 & 1 \\
\hline 283 & $-\ldots$ & 11 & 54 & 842 & . & 16 & 93 & 1104 & - & 1 & 13 \\
\hline 285 & .........., & 43 & 102 & 843 & $\ldots$ & 104 & 332 & 1106 & ................. & 8 & 33 \\
\hline 291 & …… & 13 & 38 & 858 & ..... & 29 & 83 & 1113 & . & 28 & 87 \\
\hline 293 & ........ & 13 & 46 & 860 & $-\bar{n}$ & 0 & 8 & 1114 & $=$ & 44 & 143 \\
\hline 294 & -1 & 5 & 27 & 866 & $\ldots$ & 6 & 26 & 1115 & 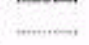 & 34 & 75 \\
\hline 295 & 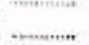 & 26 & 73 & 868 & 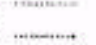 & 10 & 21 & 1118 & -1 & 41 & 102 \\
\hline 303 & $\ldots$ & 36 & 119 & 889 & 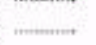 & 15 & 38 & 1160 & $\ldots$ & 50 & 159 \\
\hline 311 & 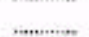 & 24 & 62 & 890 & .......... & 12 & 25 & 1163 & ........... & 22 & 67 \\
\hline $\begin{array}{l}011 \\
314 \\
314\end{array}$ & $\cdots$ & 8 & 24 & 901 & - & 7 & 27 & 1164 & - & 90 & 241 \\
\hline 315 & …… & 0 & 5 & 990 & $-\cdots$ & 0 & 1 & 1210 & - & 0 & 29 \\
\hline $\begin{array}{l}310 \\
324\end{array}$ & …..... & 1 & 11 & 1011 & 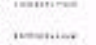 & 13 & 74 & 1221. & $\square$ & 45 & 121 \\
\hline 333 & 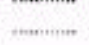 & $\overline{5}$ & 19 & 1013 & - & 8 & 37 & 1234 & $\ldots$ & 15 & 53 \\
\hline 338 & $-\ldots$ & 11 & 42 & 1015 & $\ldots$ & 3 & 11 & 1236 & $\ldots$ & 6 & 34 \\
\hline $\begin{array}{l}300 \\
341\end{array}$ & 5 & $\begin{array}{l}11 \\
13\end{array}$ & 33 & 1017 & 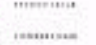 & 10 & 29 & 1247 & …........ & 12 & 37 \\
\hline 346 & 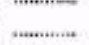 & 68 & 234 & 1030 & 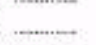 & 2 & 14 & 1248 & -3 & 25 & 39 \\
\hline $\begin{array}{l}349 \\
349\end{array}$ & $-\ldots-1$ & 16 & 41 & 1031 & $\square$ & 35 & 155 & 1270 & $\ldots$ & 5 & 23 \\
\hline 353 & 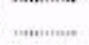 & 5 & 17 & 1032 & $\ldots$ & 14 & 58 & 1273 & ……... & 22 & 58 \\
\hline 354 & ..ㄴ... & 24 & 64 & 1033 & $\ldots$ & 25 & 62 & 1281 & . & 13 & 50 \\
\hline 647 & -- & 25 & 84 & 1054 & $\bar{\ldots}$ & 56 & 157 & 1282 & ............ & 29 & 105 \\
\hline 649 & ..... & 40 & 141 & 1055 & $\ldots$ & 1 & 2 & 1285 & … & 0 & 2 \\
\hline 653 & .......... & 25 & 71 & 1056 & 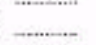 & 27 & 61 & 1290 & 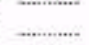 & 17 & 41 \\
\hline 674 & - & 2 & 15 & 1066 & $\ldots$ & 17 & 75 & 1292 & & 88 & 264 \\
\hline 691 & $\ldots$ & $\overrightarrow{5}$ & 8 & 1068 & $-\ldots$ & 1 & 10 & 1376 & . & 51 & 162 \\
\hline $\begin{array}{l}709 \\
709\end{array}$ & - & $\begin{array}{r}12 \\
\end{array}$ & 37 & 1072 & $\overline{n-m}$ & 7 & 15 & & & & \\
\hline 711 & $\ldots$ & 3 & 5 & 1082 & $\ldots$ & 53 & 114 & & & & \\
\hline 734 & 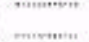 & 1 & 3 & 1083 & . & 4 & 2 & Subtot & tal _... & 685 & 2049 \\
\hline 748 & 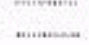 & 16 & 56 & 1084 &. & 3 & 3 & & & & \\
\hline b & & & 1618 & Subt & $\mathrm{tal} \ldots .$. & 554 & 1799 & Toto & al .... & 1732 & 5466 \\
\hline
\end{tabular}

be judged as showing a significant deficiency of recessives, they do raise the question whether there is not in reality such a deficiency, either of slight extent, or even possibly as great as has been found for some of the homozygote dominants.

(iv) A group of matings of type $+/ \mathrm{PR} X+/ \mathrm{QR}$ produce not only a recognizable quarter of recessives, but also homozygotes in $\mathrm{R}$ distinguishable from the heterozygotes. In respect of crossing over between $Q$ and $R$, two of the crossover classes will appear among the heterozygotes and dominant homozygotes respectively, while 
the two other classes are recognizable. We therefore subtract half the observed crossovers from each of these two classes; other types of crossovers are recognized and may be ignored. Table VI gives the matings of this group.

TABLE VI

MATINGS OF TYPE +/PRx + /QR

\begin{tabular}{rrrrr}
\hline Mating & $+/+$ & Heterozygous Homozygous & Orossovers \\
\hline 366 & 14 & 25 & 11 & - \\
390 & 11 & 35 & 13 & - \\
1069 & 3 & 7 & 2 & - \\
1117 & 68 & 146 & 71 & - \\
1119 & 21 & 61 & 25 & 6 \\
\hline & 117 & 274 & 122 & 6 \\
& & 3 & 3 & \\
& & 271 & 119 & \\
\hline
\end{tabular}

In this group the recessive homozygotes show a deficiency even greater than that shown by the dominant homozygotes; the data, are, however, quite insufficient to stand alone. They may, by throwing heterozygous and homozygous dominants together, be combined with Table IV showing together just such a slight excess of reces -

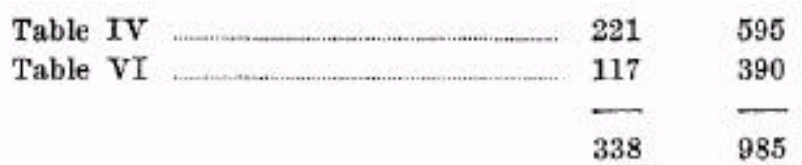

sives as might be ascribable to the lower viability of the homozygous dominants, though the ratios are too heterogeneous for such an interpretation to be relied on. Finally we may throw together all the evidence on homozygous recessives by calculating from each table the expectation, based where possible on the heterozygotes observed.

The deficiency of eighty-four in all is, of course, not significant, though it may well be that the homozygous recessives are really less viable than the heterozygotes to the extent of about 3 or 4 per cent. 
TABLE VII

SUMMARY FOR RECESSIVES

\begin{tabular}{crc}
\hline & Expected & Observed \\
\hline Table II & 91 & 93 \\
Table IV & 198 & 221 \\
Table V & 1,822 & 1,732 \\
Table VI & 136 & 117 \\
\hline Total & 2,247 & 2,163 \\
\hline
\end{tabular}

The finding of inferior viability among the homozygous dominants in Apotettix supports the view that the dominant patterns are in nature advantageous, not only by verifying a previously unsuspected fact deduced from this view, but by opening out the possibility of the direct experimental determination of the magnitude of the selective advantage of one color pattern over another in nature. For if $a, b$ and $c$ are proportional to the numbers of offspring left, on the average, by homozygous recessives, heterozygotes and homozygous dominants, respectively, then the ratio of recessive to dominant gametes will tend to approach the equilibrium value $(b-c) /(b-a)$. If therefore we are given the frequency of the different types in the natural population and can also determine experimentally the relative viabilities, and if necessary, also the fertilities in culture, we shall be in a position to infer the existence, and if our data are sufficiently accurate, to calculate the magnitude, of any selective advantage not due to constitutional causes, which in nature favors the dominants over the recessive. With increasingly precise data upon these points therefore it should be possible to put this interpretation of the dominance phenomena in the grouse locusts to a quantitative test.

\section{LEBISTES}

The condition found by Winge (1927) in Lebistes reticulatus, while showing some striking similarities, also differs in two important respects from that found in the grouse locusts. These are, first, that, with one excep- 
tion, the genes found are sex-linked in inheritance; and secondly, that, with the exception of the autosomal gene in its homozygous condition, they are without visible effects in the female (save in certain females of inter-sexual character). In this fish the male is the heterogametic sex, so that without the transference of genes by crossing over from the $\mathrm{X}$ to the $\mathrm{Y}$ chromosome, or vice versa, it would be impossible to observe the phenomena of dominance in the sex-linked factors. Such transference, has, however, been observed in several cases and, when the same factor is introduced into a male, both in its $\mathrm{X}$ and its $\mathrm{Y}$ chromosome, the fish is somatically like one into which it is introduced from one side or the other only. As far as is known, therefore, the sex-linked genes for color variants in the male may be said to be dominant, although it should be observed that Haldane's statement that "Winge found eighteen genes dominant to the normal and none recessive" is an induction from the cases so far observed, rather than a directly observed fact. The autosomal gene is also dominant in the male though it should be more properly described as recessive in the female, since it is only in the homozygous female that the striping (zebrinus) has been yet observed.

Dr. Winge informs me that the males are certainly polymorphic in nature, though the types obtainable from dealers are often more "beautiful" than those which can be found wild, thus suggesting that appreciable modi fication and gene combination have been bought about by human selection. His observations suggest the important conclusion that the $\mathrm{X}$ chromosome is usually "empty" (i.e., the universal recessive), in wild specimens, and that the genes for additional color patterns in the males are, in nature, more fully confined to the $\mathrm{Y}$ chromosome than is the case in the domesticated breeds.

We have here a group of facts extremely suggestive of the interpretation, which we should at once infer from the view that dominance has been determined by selective agencies, namely, that the color variants are advantageous in the male and disadvantageous in the female. 
Given the fundamental conditions for the stability of gene ratio, upon which any permanent Mendelizing polymorphism must rest, such a situation will lead, on our view, to consequences remarkably consonant with the facts observed. First, the variant form should become dominant in the male and recessive in the female fish; next, continued counter-selection in the female should obliterate entirely, in this sex, the effects of those genes which were capable of leaking into the $\mathrm{X}$ chromosome; thirdly, favorable selection in the males with counterselection in the females should make the variants rarer in nature in the $\mathrm{X}$ chromosome than in the $\mathrm{Y}$, although, in the absence of selection, crossing over should tend to equalize the proportions; fourthly, favorable selection in the $\mathrm{Y}$ chromosome, with counter-selection in the $\mathrm{X}$, must constantly favor those genotypes in which linkage with the sex-determining portion of the $\mathrm{Y}$ chromosome is closest, and may thus have built up the system of close sex-linkage which is now found; fifthly, close linkage with $\mathrm{Y}$ may have enabled certain variants, beneficial in the male, to have established genetic stability, which, had they been autosomal, would have been definitely deleterious, and have never contributed to the natural polymorphism. It may be a coincidence that the one variant whose effect has not been entirely suppressed in the female is the only one that still stands outside the sexlinked system; even without unduly stressing this fact, however, it is difficult to imagine how the observed facts in Lebistes could more closely simulate those to be anticipated on the theory of the selective modification of dominance.

\section{HELIX}

The facts so far available as to polymorphism in the land snails, for which Helix hortensis and nemoralis may be taken as typical, seem closely to resemble those in the grouse locusts. A great variety of distinct forms exists in nature, and of these one of very general occurrence, and frequently the commonest, appears to be a universal 
recessive. Captain Diver (1929) has ascertained that various forms now found appear without perceptible change in the proportions among Pleistocene remains, and we may somewhat confidently infer from this a definite mechanism of stability in the gene-ratios. Breeding experiments, of which few unfortunately have yet been published, appear to show, so far, complete linkage between the different factors, although types which may have arisen originally by recombination are found in nature.

Thus we find the three peculiar features, of polymorphism, close linkage and the universal recessive type of dominance, occurring together in groups as widely separated as are mollusks, vertebrates and insects, and we can scarcely doubt that the three phenomena are associated causally. While it is at present certainly premature to choose one of these three as the primary cause responsible for the other two, it is perhaps worth while, even now, to consider, in a spirit of conjecture, whether the close linkage may not, at least in the snails and grouse locusts, have played the primary role.

\section{EVOLUTIONARY CONDITIONS INDUCED BY CLOSE LINKAGE}

Close linkage within and especially between chromosomes introduces one difficulty to normal evolutionary development which has not, I think, been recognized. While its ultimate discussion will undoubtedly require far more refined mathematical development than I can here attempt, it does seem possible to gain a crude qualitative notion of its nature by considering the extreme, and perhaps unreal, case of a species in which no recombination whatever is possible. Any considerable change, in the evolution of a species from its ancestral form at a remote geological period, must have involved numerous genetic substitutions. The genetic novelties ultimately adopted must, as far as we know, have originated in mutations, though where free recombination is possible, we need by no means confine ourselves to the supposition that such mutations must necessarily have been bene- 
ficial from their first appearance. It is indeed certain that many species contain a large amount of latent variability by the selection of which their instantaneous rates of evolutionary improvement are maintained. There is no need, however, to suppose that the whole of this is due to a stream of mutations beneficial from their first appearance, in process of spreading over the species, rather than that much of it may be due to effectively neutral mutations which have occurred in the past, and the ultimate fate of which is at present in process of decision. However this may be, in a species entirely devoid of recombination, and possessing for genetic purposes only a single gene, a beneficial substitution which could be adopted without hindrance, in a species enjoying the advantage of free recombination, will be threatened by every other genetic substitution possible within the genetic variance of the species, and will inevitably be pushed aside and suppressed if any such alternative substitution offers a greater selective advantage. The different genotypes will, in fact, compete with one another like a system of multiple allelomorphs, and instead of genetic improvement being possible simultaneously in hundreds of different loci, the steps of evolutionary improvement will have to take place one at a time, the weaker always making way for the stronger.

The chance of any particular substitution being adopted may be crudely represented as the chance that during a certain time, during which it is spreading through the species, no substitution more suitable than itself makes its appearance. If we represent by $a$ the selective advantage of a substitution and by $\mu_{\mathrm{a}} d a$ the frequency with which substitutions in the range $d a$ present themselves, the time needed for the substitution to spread, within any assigned limits, over the population will be inversely proportional to $a$, while the frequency with which substitutions superior to any given level $b$ appear will be represented by 


$$
\int_{b}^{\infty} \mu_{a} d a
$$

where $\mu_{a}$ doubtless falls off rapidly as $a$ is increased. Consequently if $b$ represents a level of advantage which has a tolerable chance of survival, before some bigger advantage can thrust it aside, we shall have some such relation as

$$
b c=\int_{b}^{\infty} \mu_{a} d a
$$

where $c$ is a constant, dependent upon the chance or survival chosen. For a suitably chosen constant, $b$ may be regarded as a standard level of selective advantage such that substitutions giving a selective advantage greater than $b$ can and do prevail over their competitors, and so contribute to evolutionary progress, while those conferring a much smaller selective advantage have scarcely any chance of doing so. There will, in fact, in such cases be something like a real limen of selective advantage, such as Sewall Wright has suggested even for cases involving free recombination. It is not unreasonable to suspect that the chance of success for selective advantages less than $b$ may be proportional to $e^{-b} /^{a}$, an expression that diminishes with extreme rapidity as $a$ is diminished, although when $a$ is so small that the expression approaches $1 /(2 n)$, where $n$ is the number of parents breeding in each generation, the probability must remain nearly constant until $a$ falls to zero.

For the more practical case, in which some degree of recombination is possible, the state of affairs appears at first sight to be similar, though with a larger value of the constant $c$, which may be expected to increase with increasing recombination, in proportion to the number of separable loci in the species; and, unsatisfactory as such a crude approach must be felt to be, it does seem to show with sufficient clarity that when linkage is, as with the species here considered, extremely close, it will be impossible to utilize a number of the smaller genetic improve- 
ments which present themselves, because the whole of the existing nuclear material is fully occupied with matters of more importance.

Now the system of obtaining improved color patterns, such as appears to fit the facts with the grouse locusts, by dominant duplications, which are deleterious in the homozygous phase, at once raises the problem of why the universal recessive can not itself be modified to a more advantageous pattern, and so supersede the dominants with which it appears to be now in equilibrium. There is little harm in putting forward a conjecture so long as it is clearly recognized as such, and it appears to the writer possible that the color pattern of the grouse locust is not among the more important matters with which its evolutionary progress is urgently concerned. What these more important matters are it would be idle to guess-perhaps its digestion or its vision or its reproductive instincts may be of greater real importance to the insect; at least we can not fairly assume that the real importance of a feature is in any way measured by its conspicuousness to ourselves, and we have no reason at present to assume without question that the universal recessive, in species with such close linkage as the grouse locusts, is free to seize upon any such relatively trifling advantage as might be gained by modifying its color pattern.

This point of view brings out, I think, one of the most attractive features of the theory of duplications, for if modifications in color pattern are too unimportant to win their way to success in the germ-plasm of the universal recessive, it is clear that modifications of the heterozygote must be due to factors located elsewhere, and the theory supplies a tract of chromatin where such factors, though they may compete among themselves, are protected from outside competition. On this view the evolution of dominance would have taken place by the selective modification of the duplication itself. The same of course could be said, without duplication, of any tract permanently associated with the dominant gene. 


\section{SUMMARY}

Polymorphism in wild populations must usually imply a balance of selective agencies, of which the simplest type is a selective advantage of the heterozygote over both homozygotes. Such a condition should not be confused with the maintenance of a rare mutant type against counterselection by means of repeated mutations. While such mutations should on the theory of the selective modification of dominance tend to become recessive, heterozygotes in polymorphic species will tend to resemble in external appearance whichever homozygote it is most advantageous to resemble. The selective balance must then be maintained by some constitutional disadvantage of the homozygous dominant.

The modification of dominance should in such cases be especially rapid; partly by reason of the far greater frequencies of the heterozygotes exposed to selection, and partly, if any tract of chromatin is permanently associated with the dominant gene, from the fact that the evolutionary modification of such a tract will be reserved for the improvement of the heterozygote, and in less degree of the corresponding homozygote.

Nabours' experiments with the grouse locust Apotettix do, in fact, show such a deficiency of homozygous dominants as is required by this theory. The average amount of the deficiency is about 7 per cent. In six individual cases the deficiency is statistically significant, and six more show a non-significant deficiency, against two showing a nonsignificant excess.

It is not certain from the existing data whether the homozygous recessive is equivalent in viability to the heterozygotes, or suffers also from a slight defect in viability. Deliberate experiments on the viability of the different genotypes together with counts of the frequencies in nature would enable the inference that the dominants really exhibit the more advantageous patterns to be put to a quantitative test.

The incidence of dominance and linkage in the fish $L e$ bistes reticulatus strongly suggests that the colored genes 
found by Winge are advantageous in the male but disadvantageous in the female.

The association of the three peculiarities of polymorphism, close linkage and the universal recessive type of dominance is found in mollusks, arthropods and vertebrates. It is tentatively suggested that, at least in the grouse locusts and the snails, the primary cause of the two other phenomena may be found in the closeness of linkage within or between chromosomes. This condition presents an obstacle to normal evolutionary development by gene substitution, and so makes it possible for abnormalities such as duplications to possess occasional advantages, so setting up the stability of the gene-ratio necessary for polymorphism; if the advantage lies in the external appearance, the polymorphism will be manifest, and the variant form will tend to become dominant.

M. Demerec

\section{LITERATURE CITED}

1928. "A Possible Explanation for Winge's Findings in Lebistes reticulatus," AM. NAT., 62: 90-94.

C. Diver

1929. "Fossil Records of Mendelian Mutants," Nature, 124: 183.

R. A. Fisher

1927. "On Some Objections to Mimicry Theory, Statistical and Ge netic," Trans. Ent. Soc. London, 75: 269-278.

1928a. "The Possible Modification of the Response of the Wild Type to Recurrent Mutations," AM. NAT ., 62: 115-126.

1928b. "Two Further Notes on the Origin of Dominance," AM. NAT., 62: $571-574$.

J. B. S. Haldane

1920. "Note on a Case of Linkage in Paratettix," Jour. of Genetics, 10: 47-52.

1930. "A Note on Fisher's Theory of the Origin of Dominance and on a Correlation between Dominance and Linkage," AM. NAT ., 64: 87-90. R. K. Nabours

1925. "Studies of Inheritance and Evolution in Orthoptera, V.,"

O. Winge Kans. Agr. Exp. Sta. Tech. Bul. No. 17.

1927. "The Location of Eighteen Genes in Lebistes reticulatus," Jour. of Genetics, 18: 1-43. 